\title{
Exigência de lisina para poedeiras semipesadas durante o pico de postura ${ }^{1}$
}

\author{
José Jordão Filho², José Humberto Vilar da Silva ${ }^{3}$, Edson Lindolfo da Silva ${ }^{4}$, Marcelo Luís \\ Gomes Ribeiro ${ }^{2,5}$, Fernando Guilherme Perazzo Costa ${ }^{6}$, Paulo Borges Rodrigues ${ }^{7}$
}

\author{
${ }^{1}$ Parte da dissertação de Mestrado do primeiro autor apresentada ao PPGZ/CCA/UFPB, Areia - PB. \\ 2 Doutorado Integrado em Zootecnia, PDIZ/CCA/UFPB, Areia - PB. Bolsista CAPES. \\ ${ }^{3} \mathrm{DAP} / \mathrm{CFT} / \mathrm{UFPB}$, Bananeiras - PB e PPGZ - CCA/UFPB, Areia, PB. Bolsista PQ - CNPq. \\ ${ }^{4}$ Doutorando em Zootecnia, UFLA, Lavras - MG. \\ ${ }^{5} \mathrm{DAP} / \mathrm{CFT} / \mathrm{UFPB}$, Bananeiras $-P B$. \\ ${ }^{6} P P G Z-C C A / U F P B$, Areia - PB. \\ 7 UFLA, Lavras - MG.
}

RESUMO - Objetivando determinar as exigências nutricionais de lisina para 252 poedeiras semipesadas, foi conduzido um experimento em delineamento inteiramente ao acaso, com sete tratamentos, constituídos de seis repetições de seis aves. As dietas, isoprotéicas $(17,1 \%$ de $\mathrm{PB})$ e isocalóricas $(2.800 \mathrm{kcal} / \mathrm{kg}-\mathrm{EM})$, foram formuladas para atender às exigências das aves em todos os nutrientes, exceto lisina, que foi suplementada com L-lisina $-\mathrm{HCl}$ (78,4\% de lisina), resultando nos seguintes níveis: 0,79 ; 0,$83 ; 0,87 ; 0,91 ; 0,95 ; 0,99$ e $1,03 \%$ de lisina total. As características de desempenho foram avaliadas no período de 30 a 46 semanas de idade, que corresponde ao pico de postura. Foi observado efeito quadrático dos níveis de lisina sobre a produção, o peso e a conversão alimentar por dúzia de ovos. As exigências de lisina total foram de 0,92;0,91 e 0,90\%, que correspondem, respectivamente, a 0,$84 ; 0,83$ e $0,82 \%$ de lisina digestível. Recomenda-se 0,92 ou $0,84 \%$, ou 996 ou $910 \mathrm{mg}$, de lisina total e digestível/ave/dia para poedeiras semipesadas durante o pico de postura.

Palavras-chave: aminoácido total, desempenho, nutrição

\section{Lysine requeriment of semi-heavy laying hens during the peak of egg production}

\begin{abstract}
An experiment was carried out as a completely randomized design, with seven treatments, and six replicates of six birds to determine the lysine nutritional requeriments for 252 semi-heavy laying hens. The diets were formulated to be isonitrogenous $(17.1 \% \mathrm{CP})$ and isoenergy $(2,800 \mathrm{kcal} / \mathrm{kg}-\mathrm{ME})$ and to meet all bird nutrient requeriments, with the exception of lysine, that was supplemented with L-lysine $-\mathrm{HCl}(78.4 \%$ of lysine) and resulted in the following levels: $0.79,0.83,0.87$, $0.91,0.95,0.99$, and $1.03 \%$ of total lysine. The performance variables were evaluated from 30 to 46 weeks of age, that correspond to the peak of egg production in commercial hens. Quadract effect of treatments on egg production, egg weight and egg dozen:feed ratio was observed. The total lysine requeriments were of $0.92,0.91$, and 0.90 , that was correspondent to the estimate of $0.84,0.83$, and $0.82 \%$ of digestible lysine, respectively. It is recommended levels of 0.92 or $0.84 \%$ or intake of 996 or $910 \mathrm{mg}$ of total and digestible lysine/bird/day, during the peak of egg production.
\end{abstract}

Key Words: nutrition, performance, total amino acids

\section{Introdução}

No Brasil e na maioria das regiões do mundo, as rações para poedeiras são formuladas à base de milho e farelo de soja, que, normalmente, suprem as necessidades das aves em energia e proteína, mas não completamente em aminoácidos essenciais.

A alimentação constitui mais que $65 \%$ do custo de produção de poedeiras (Ribeiro et al., 2003; Togashi et al., 2002) e a proteína (aminoácidos) é o nutriente que mais onera o custo final da ração, pondo em risco a rentabilidade das criações.
A eficiência de utilização dos nutrientes da ração pelas aves depende de muitos fatores. Por exemplo, o excesso ou a deficiência dos aminoácidos essenciais afeta diretamente sua eficiência de utilização (Baker et al., 2002), assim como o perfil (Schutte \& De Jong, 1994; Baião et al., 1999) e a disponibilidade biológica dos aminoácidos na matériaprima (Barbosa et al., 1999).

A lisina é o segundo aminoácido limitante nas rações para aves e o interesse por estudos com este aminoácido na alimentação de poedeiras se justifica principalmente pelo fato de que a lisina apresenta baixo custo de suplementação 
e pode afetar a deposição de proteína corporal (Valério et al., 2003) e dos ovos (Ribeiro et al., 2002), além do teor de sólidos totais (Novak et al., 2004), e, possivelmente, melhorar as propriedades funcionais do ovo como matéria-prima para a indústria alimentícia. Além disso, a estimativa das exigências de lisina pode ser o ponto de partida para a formulação de rações com base no conceito de proteína ideal, em que a lisina é o aminoácido de referência (Pack, 1995; Silva et al., 2005).

Estudos têm sido realizados para avaliar as exigências diárias de lisina para aves semipesadas. Entretanto, tem-se sugerido valores discrepantes, como $816 \mathrm{mg}$ (Novak et al., 2004) para poedeiras de 44 a 63 semanas de idade; $880 \mathrm{mg}$ (Barbosa et al., 1999) para aves a partir de $76^{a}$ semana de idade; e $920 \mathrm{mg}$ de lisina total/ave/dia (Rostagno et al. (2005). De modo geral, as recomendações nutricionais de aminoácidos para poedeiras não têm considerado o efeito da idade e do estádio de produção, sendo normalmente apresentados valores únicos para todo o ciclo de postura. Entretanto, durante o pico de postura (de 26 a 46 semanas de idade), a produção de ovos atinge percentuais superiores a $90 \%$ sendo, provavelmente, o período em que a demanda de nutrientes se torna mais elevada, principalmente o nível de aminoácidos, para atender o máximo potencial de produção das aves. Além disso, as recomendações de aminoácidos em rações para poedeiras precisam ser atualizadas, tendo em vista o progresso genético e a possibilidade de as aves responderem de forma diferente aos diversos ambientes e às mudanças nos sistemas de produção, em que maior espaço de alojamento tem sido destinado às aves.

O objetivo neste estudo foi estimar as exigências nutricionais de lisina para poedeiras semipesadas durante o pico de postura.

\section{Material e Métodos}

O experimento foi realizado no Laboratório Avícola do Centro de Formação de Tecnólogos (CFT), Campus III da Universidade Federal da Paraíba (UFPB), situado no município de Bananeiras, na microrregião do Brejo Paraibano. Foram utilizadas 252 poedeiras semipesadas da linhagem Hisex Brown com 30 semanas de idade e peso vivo médio de $1,7 \pm 0,06 \mathrm{~kg}$. Na seleção das aves, foram considerados o peso vivo e a produção de ovos no período pré-experimental (14 dias de duração).

Foram alojadas duas aves por gaiola convencional medindo ( $25 \times 45 \times 40 \mathrm{~cm}$ ), distribuídas em um galpão experimental coberto com telhas de barro em duas águas, orientação leste-oeste, pé-direito de 1,8 m de altura, duas fileiras de gaiolas sobrepostas e um corredor central de
$1 \mathrm{~m}$ de largura entre as fileiras de gaiolas. O experimento foi conduzido no período de 30 a 46 semanas de idade das poedeiras. As temperaturas e as umidades relativas do ar mínimas e máximas foram, respectivamente, de 23,5 $\pm 3,3$ e $27,42 \pm 2,7^{\circ} \mathrm{C}$ e $81,48 \pm 7,1$ e $87,31 \pm 5,9 \%$ pela manhã $(8 \mathrm{~h})$ e à tarde (16h) e o programa de iluminação foi de 17 horas/dia.

Foi adotado delineamento experimental inteiramente ao acaso, com sete tratamentos constituídos pelos níveis de lisina total: 0,$79 ; 0,83 ; 0,87 ; 0,91 ; 0,95 ; 0,99$ e $1,03 \%$ e seis repetições com seis aves. Foi utilizada uma ração basal $(17,1 \% \mathrm{~PB}, 2.800 \mathrm{kcal} \mathrm{EM} / \mathrm{kg})$ deficiente em lisina $(0,79 \%$ de lisina total) suplementada com sete níveis de L-lisina - $\mathrm{HCl},(78,4 \%$ de atividade de lisina) para proporcionar os níveis de 0,$05 ; 0,10 ; 0,15 ; 0,20 ; 0,25 ; 0,30$ e $0,35 \%$ em substituição ao amido de milho. As rações estudadas (isoprotéicas e isocalóricas) foram formuladas de acordo com as sugestões de Rostagno et al. (2000), Tabela 1.

Os teores protéicos e energéticos dos ingredientes e os valores totais e digestíveis da lisina, do milho, do farelo de soja e do glúten de milho, tomados como base para a estimativa da lisina total e digestível, são descritos na Tabela 2. O fornecimento de água foi à vontade e o de ração foi feito em quantidade suficiente para permitir consumo diário de $110 \mathrm{~g}$ /ave ou $308 \mathrm{kcal}$ de EM, conforme preconizado por Rostagno et al. (2000).

As características de desempenho avaliadas foram: consumo de ração (g/a/d), produção de ovos $(\% / \mathrm{a} / \mathrm{d})$, peso (g) e massa de ovos (g/a/d), conversão alimentar por massa $(\mathrm{kg} / \mathrm{kg})$ e por dúzia de ovos $(\mathrm{kg} / \mathrm{dz})$, consumo de lisina total ( $\mathrm{mg} / \mathrm{a} / \mathrm{d})$, consumo de lisina por massa de ovos $(\mathrm{mg} / \mathrm{mo})$ e gravidade específica $\left(\mathrm{g} / \mathrm{cm}^{3}\right)$. O peso dos ovos foi o valor médio do peso dos ovos produzidos nos últimos cinco dias de cada fase experimental. A massa de ovos representou o produto da porcentagem de ovos produzidos de cada período pelo peso médio dos ovos, enquanto a conversão alimentar por massa de ovos foi expressa em quilos de ração por quilo de massa de ovos produzida e a conversão alimentar por dúzia de ovos foi a quantidade de ração consumida $(\mathrm{kg})$ por dúzia de ovos produzida. A gravidade específica (GE) foi determinada pelo método recomendado por Hempe et al. (1988), por meio da relação do peso do ovo no ar e o produto do peso do ovo após imersão completa em água destilada, multiplicada pela densidade da água a $23^{\circ} \mathrm{C}$, de 0,99754, segundo a expressão:

peso do ovo no ar (g)

$\mathrm{GE}\left(\mathrm{g} / \mathrm{cm}^{3}\right)=$ x 0,99754

peso do ovo submerso em $\mathrm{H}_{2} \mathrm{O}$ destilada

As análises estatísticas foram realizadas utilizando-se o pacote estatístico SAEG - Sistema de Análises Estatísticas 
Tabela 1 - Composições alimentar e nutricional da ração basal ${ }^{1}$ Table 1 - Ingredient and chemical compositions of the basal diet

\begin{tabular}{lc}
\hline $\begin{array}{l}\text { Ingrediente } \\
\text { Ingredient }\end{array}$ & $\begin{array}{c}\text { Dieta basal } \\
\text { Basal diet }\end{array}$ \\
\hline Milho (Corn) & 61,86 \\
Farelo de soja (Soybean meal) & 19,96 \\
Glútem de milho (Corn gluten) & 4,20 \\
Calcário (Limestone) & 9,94 \\
Fosfato bicálcico (Dicalcium phosphate) & 1,51 \\
Amido (Starch) & 0,84 \\
DL-metionina (DL-methionine) & 0,18 \\
L-lisina $\bullet H C l$ (L-lysine HCl) & 0,05 \\
Cloreto de colina (70\%) (C. chloride) & 0,20 \\
Óleo vegetal (Vegetable oil) & 0,45 \\
Sal comum (Salt) & 0,55 \\
Premix vitaminíco ${ }^{2}$ (Vitamin mix) & 0,20 \\
Premix mineral ${ }^{3}$ (Mineral mix) & 0,05 \\
Inerte $^{4}$ (Inert) & 0,01 \\
Total $^{\text {Cotal }}$ & 100,00
\end{tabular}

Composição química

Chemical composition

Proteína bruta (\%) (Crude protein)

Energia metabolizável (ME) $(\mathrm{kcal} / \mathrm{kg})$

Gordura (\%) (Fat)

2,990

$\mathrm{Ca}(\%)$

$\mathrm{P}$ disponível (\%) (Available P)

Metionina+cistina $(\%) \mathrm{T}^{5}$

Methionine+ cystine (\%) $T$

Metionina + cistina $(\%) \mathrm{D}^{5}$

4,210

0,372

0,765

Methionine+ cystine (\%) D

Metionina (\%) $\mathrm{T}$

Methionine (\%) $T$

Metionina (\%) D

Methionine (\%) D

Lisina (\%) T (Lysine)

0,699

0,481

0,391

Lisina (\%) D (Lysine)

0,790

0,704

0,912

Arginine (\%) $T$

Arginina (\%) D

0,852

Arginine (\%) $D$

Fenilalanina + Tirosina $(\%)$

1,520

Phenylalanine + Tyrosine (\%)

Isoleucina (\%) T (Isoleucine)

0,601

0,647

0,483

Treonina (\%) D (Threonine)

0,180

0,150

0,673

0,594

1,348

1,240

0,251

0,321

0,563

$\mathrm{Cl}(\%)$

162,62

Balanço eletrolítico $(\mathrm{Na}+\mathrm{K}-\mathrm{Cl})(\mathrm{mEq} / \mathrm{kg})$

Acid base balance

\footnotetext{
${ }_{1}^{1}$ Recomendações de Rostagno et al. (2000) (According to Rostagno et al., 2000

2 Composição por kg do produto (Composition/kg of product): vit. A 10.000 .000 UI; vit. $D_{3} 2.500 .000$ UI; vit. E 6.000 UI; vit. K 1.600 mg; vit. $B_{12} 11.000$ mg; niacina (Niacin) $25.000 \mathrm{mg}$; ácido fólico (folic acid) $400 \mathrm{mg}$; ácido pantotênico (pantothenic acid) 10.000 mg; selênio (selenium) $300 \mathrm{mg}$; antioxidante (antioxidant) $30 \mathrm{~g}$; veículo (vehicle) q.s.p.

3 Composição por kg do produto (Composition/kg of product): $\mathrm{Mg}-150.000 \mathrm{mg}$;

Zn - 100.000 mg; Fe - 100.000 mg; Cu - 16.000 mg; I 1.500 mg; veículo (vehicle) q.s.p.

4 Inerte: areia lavada (washed sand).

${ }^{5} \mathrm{~T}$ = aminoácido total (total amino acid); $\mathrm{D}$ = aminoácido digestível (digestible amino acid).
}

Tabela 2 - Composições protéica e energética dos ingredientes e valores totais e digestíveis de lisina do milho, do farelo de soja e do glúten de milho

Table 2 - Protein and energy compositions of ingredients and values of total and digestible lysine of corn, soybean meal and corn gluten

\begin{tabular}{|c|c|c|c|c|}
\hline $\begin{array}{l}\text { Ingrediente } \\
\text { Ingredient }\end{array}$ & $\begin{array}{l}\mathrm{PB} \\
(\%) \\
C P\end{array}$ & $\begin{array}{l}\text { EMAn } \\
(\mathrm{kcal} / \mathrm{kg}) \\
\quad M E\end{array}$ & $\begin{array}{c}\text { Total } \\
\text { Total }\end{array}$ & $\begin{array}{c}\text { Digestível }^{3} \\
\text { Digestible }\end{array}$ \\
\hline $\begin{array}{l}\text { Milho }^{1} \\
\text { Corn }\end{array}$ & 8,57 & 3.371 & 0,25 & 0,203 \\
\hline $\begin{array}{l}\text { Farelo de soja }{ }^{1} \\
\text { Soybean meal }\end{array}$ & 45,54 & 2.266 & 2,78 & 2,53 \\
\hline $\begin{array}{l}\text { Glúten de milho }(60 \%)^{1} \\
\text { Corn gluten }\end{array}$ & 59,85 & 3.775 & 1,00 & 0,90 \\
\hline $\begin{array}{l}\text { Amido }^{1} \\
\text { Starch }\end{array}$ & 0,55 & 3.625 & & \\
\hline $\begin{array}{l}\text { DL-metionina }(0,99 \%)^{2} \\
\text { DL-methionine }\end{array}$ & 58,7 & 3.680 & & \\
\hline $\begin{array}{l}\text { L-lisina } \bullet \mathrm{HCl}(78,4 \%)^{2} \\
\text { L-lysine } \mathrm{HCl}\end{array}$ & 119,8 & 4.600 & & \\
\hline $\begin{array}{l}\text { Óleo vegetal }{ }^{1} \\
\text { Vegetable oil }^{1}\end{array}$ & 0 & 8.790 & & \\
\hline
\end{tabular}

1 Segundo Rostagno et al. (2000)(According to Rostagno et al., 2000 tables).

2 Segundo NRC (1994) (According to NRC, 1994 tables).

${ }^{3}$ Valores constantes em Rostagno et al. (2000) (According to Rostagno et al. 2000).

e Genéticas, desenvolvido pela Universidade Federal de Viçosa-UFV (1993). As estimativas das exigências de lisina foram estabelecidas por meio do modelo de regressão polinomial, considerando-se o valor do coeficiente de determinação e a resposta biológica das aves.

\section{Resultados e Discussão}

Os resultados referentes ao consumo de ração, à produção de ovos, ao peso e à massa de ovos das poedeiras semipesadas durante o pico de postura, em função dos diferentes níveis de lisina das rações experimentais, são apresentados na Tabela 3 .

O consumo não foi influenciado pelos níveis de lisina da ração $(\mathrm{P}>0,05)$, o que corrobora os resultados obtidos por vários autores (Barbosa et al., 1999; Novak et al., 2004; Sá et al., 2004), que também não observaram efeitos dos níveis de lisina sobre esta característica. Em contrapartida, Carvalho et al. (2003) verificaram efeito linear da lisina total sobre a ingestão de alimento em poedeiras leves de 44 a 55 semanas de idade. Entretanto, a resposta encontrada pelos autores pode ter sido influenciada pelo fato de terem sido utilizados no estudo níveis de lisina abaixo da exigência das aves.

A produção de ovos foi significativamente influenciada $(\mathrm{P} \leq 0,05)$ pelos níveis de lisina, conforme o seguinte modelo de regressão polinomial: $\hat{\mathrm{Y}}=-152,77+531,82 \mathrm{X}-290,1 \mathrm{X}^{2}$ $\left(\mathrm{R}^{2}=0,74\right)$ (Figura 1$)$, com resposta máxima de produção em 
Tabela 3 - Consumo de ração (CR), produção de ovos (PR), peso de ovos (PO) e massa de ovos (MO) em função dos níveis de lisina na ração

Table 3 - $\quad$ Feed intake (FI), egg production (EP), egg weight (EW) and egg mass (EM) as affected by the dietary total lysine levels

\begin{tabular}{lcccc}
\hline $\begin{array}{l}\text { Nível de lisina } \\
\text { total (\%) }\end{array}$ & CR $(\mathrm{g} / \mathrm{d})$ & $\begin{array}{c}\text { PR }(\%) \\
E P\end{array}$ & $\begin{array}{c}\text { PO }(\mathrm{g} / \mathrm{d}) \\
E W\end{array}$ & $\begin{array}{c}\mathrm{MO}(\mathrm{g} / \mathrm{d}) \\
E M\end{array}$ \\
\begin{tabular}{l} 
Total lysine \\
\hline 0,79
\end{tabular} & & & & \\
0,83 & 108,08 & 86,10 & 65,57 & 57,08 \\
0,87 & 107,46 & 89,30 & 65,40 & 59,29 \\
0,91 & 108,18 & 90,10 & 64,69 & 58,31 \\
0,95 & 108,39 & 91,38 & 64,86 & 57,35 \\
0,99 & 108,28 & 88,99 & 65,15 & 57,96 \\
1,03 & 109,09 & 91,16 & 64,55 & 59,10 \\
& 108,69 & 86,66 & 66,15 & 57,35
\end{tabular}

ANOVA

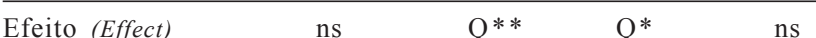

$\mathrm{R}^{2}$

\section{CV $(\%)$}

0,983

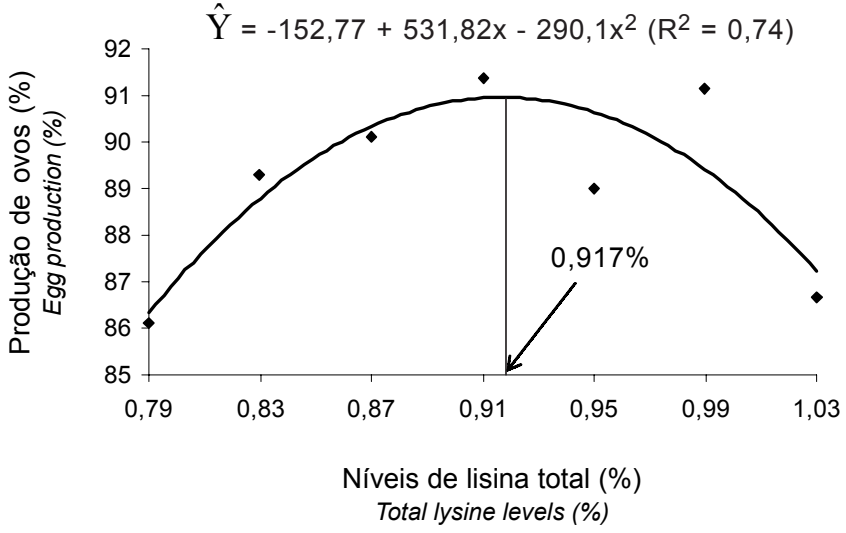

Figura 1 - Produção de ovos em função dos níveis de lisina total da ração.

Figure 1 - Egg production as affected by the dietary total lysine levels.

nismo lisina-arginina, o excesso de lisina afeta a absorção de arginina pela competição em nível de sítio de transporte, tendo em vista a semelhança estrutural entre esses dois aminoácidos. Além disso, o excesso de lisina contribui para o aumento do catabolismo de arginina pela arginase renal (D'Mello, 2000), possivelmente aumentando ainda mais a deficiência de arginina das aves, que não dispõem de ciclo da uréia funcional e de uma fonte endógena de arginina.

Da mesma forma, Silva et al. (2004), avaliando diferentes relações lisina:arginina digestível para poedeiras, sugeriram relação de 101 ou $0,72 \%$ de lisina e $0,71 \%$ de arginina. Gadelha et al. (2003) observaram redução no desempenho e alta incidência de problemas de pernas em frangos de corte com o aumento do nível de lisina $(0,95 ; 1,19 ; 1,43 ; 1,66$ e $1,90 \%$ ) da ração (com 1,06\% de arginina). Todavia, com o aumento do nível de arginina de 1,06 para 2,13\%, os efeitos redutores desapareceram. Na literatura científica, existem relatos de que o excesso de lisina causa sintomas de toxidez em codornas jovens (Silva et al., 2003), pintinhos de corte (Okumura \& Yamaguchi, 1980) e pintinhas (Silva et al., 2000a). Além disso, um ponto percentual a mais de excesso de lisina acima das exigências em dietas para poedeiras pode piorar a eficiência alimentar em comparação ao excesso de metionina (Koelkebeck et al., 1991).

Efeito quadrático foi encontrado para o peso dos ovos em função dos níveis de lisina ( $\mathrm{P} \leq 0,06)$, sendo que o menor peso dos ovos foi obtido com $0,91 \%$ de lisina total na ração (Figura 2), próximo ao nível de $0,92 \%$ estimado para a máxima produção de ovos (Figura 1), o que sugere possível correlação negativa produção $\times$ peso dos ovos. Este resultado corrobora os reportados por Silva et al. (1999), que encontraram maior peso dos ovos nos tratamentos com menor produção. Sá et al. (2004) também demonstraram que altas 


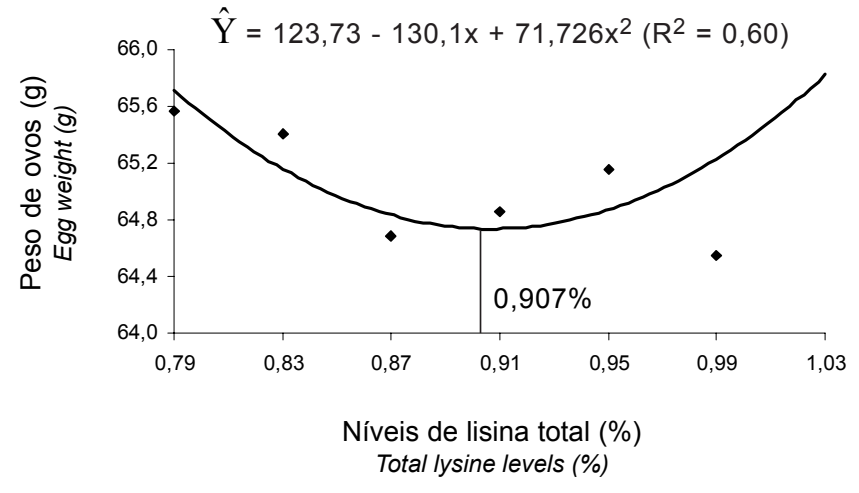

Figura 2 - Peso de ovos em função dos níveis de lisina total na ração.

Figure 2 - Egg weight as affected by the dietary total lysine levels.

taxas de postura implicam redução do peso dos ovos. Segundo Mendonça Jr. \& Lima (1999), a lisina normalmente influencia a produção de ovos, mas não aumenta o tamanho dos ovos como a metionina.

A massa de ovos não foi influenciada $(\mathrm{P}>0,05)$ pelos níveis de lisina da ração, refletindo, provavelmente, o comportamento da produção e do peso dos ovos, em que os níveis extremos de lisina da ração pioraram a produção, mas melhoraram o peso dos ovos. De modo contrário, Barbosa et al. (1999) observaram efeito quadrático dos níveis de lisina sobre a massa de ovos em poedeiras semipesadas durante o segundo ciclo de postura.

A conversão alimentar por massa e por dúzia de ovos, a gravidade específica, o consumo de lisina e o consumo de lisina por massa de ovos são apresentados na Tabela 4.

Apesar de a conversão alimentar por massa de ovos não ter sido influenciada pelos níveis de lisina $(\mathrm{P}>0,05)$, a conversão alimentar por dúzia de ovos apresentou comportamento quadrático $(\mathrm{P} \leq 0,01)$. $\mathrm{O}$ modelo de equação foi: $\hat{\mathrm{Y}}=5,3835-8,7613 \mathrm{X}+4,8512 \mathrm{X}^{2}\left(\mathrm{R}^{2}=0,80\right)$, em que a exigência para conversão foi estimada em $0,90 \%$ de lisina (Figura 3), que equivale a um consumo de $975 \mathrm{mg} / \mathrm{ave} / \mathrm{dia}$ durante o pico de postura, próximo aos $900 \mathrm{mg}$ de lisina total/ave/dia preconizados por Schutte \& Swink (1998).

Os níveis extremos de lisina da ração proporcionaram os piores resultados de conversão por dúzia de ovos, comportamento similar ao observado para a produção de ovos, em que a deficiência e o excesso de lisina da ração podem ter causado, respectivamente, desbalanço aminoacídico e antagonismo da lisina com a arginina. Resultados semelhantes quando os níveis de lisina da ração foram elevados foram observados por Goulart (1997), em poedeiras semipesadas e leves, e Ribeiro et al. (2003) e Pinto et al. (2003), em codornas japonesas em postura.
Tabela 4 - Conversão alimentar por massa de ovos (CMO), conversão por dúzia de ovos (CDO), gravidade específica (GE), consumo de lisina (CLYS) e consumo de lisina por massa de ovos (CLYS/MO) em função dos níveis de lisina total na ração

Table 4 - Eggs mass:feed ratio (EMF), eggs dozen:feed ratio (EDF) specific gravity (SG), lysine intake (LI) and eggs mass to lysine intake (EGLI) as affected by the dietary total lysine levels

\begin{tabular}{lccccc}
\hline $\begin{array}{l}\text { Nível de lisina } \\
\text { total (\%) } \\
\text { Total lysine level }\end{array}$ & $\begin{array}{c}\mathrm{CMO} \\
(\mathrm{kg} / \mathrm{kg}) \\
E M F\end{array}$ & $\begin{array}{c}\mathrm{CDO} \\
(\mathrm{kg} / \mathrm{kg}) \\
E D F\end{array}$ & $\begin{array}{c}\mathrm{GE} \\
\left(\mathrm{g} / \mathrm{cm}^{3}\right) \\
S G\end{array}$ & $\begin{array}{c}\mathrm{CLYS} \\
(\mathrm{mg})\end{array}$ & $\begin{array}{c}\mathrm{CLYS} / \mathrm{MO} \\
(\mathrm{mg} / \mathrm{g}) \\
E G L I\end{array}$ \\
\hline 0,79 & 1,900 & 1,492 & 1,087 & 853,832 & 14,958 \\
0,83 & 1,855 & 1,442 & 1,090 & 891,918 & 15,043 \\
0,87 & 1,866 & 1,446 & 1,087 & 941,166 & 16,141 \\
0,91 & 1,823 & 1,424 & 1,086 & 986,349 & 17,198 \\
0,95 & 1,874 & 1,453 & 1,092 & 1028,66 & 17,748 \\
0,99 & 1,864 & 1,439 & 1,090 & 1079,991 & 18,274 \\
1,03 & 1,916 & 1,517 & 1,088 & 1119,507 & 19,520 \\
\hline Efeito (Effect) & $\mathrm{ns}$ & $\mathrm{Q} * *$ & $\mathrm{~ns}$ & $\mathrm{~L} * *$ & $\mathrm{~L} * *$ \\
$\mathrm{R}^{2}$ & - & 0,80 & - & 1,00 & 0,98 \\
CV (\%) & 5,502 & 4,695 & 0,743 & 0,944 & 5,63 \\
\hline
\end{tabular}

$\mathrm{L}=$ efeito linear (linear effect); $\mathrm{Q}=$ efeito quadrático (quadratic effect); ns = nãosignificativo (not significant)

${ }^{*}(P \leq 0,05) ;{ }^{* *}(P \leq 0,01)$.

$\mathrm{CV}=$ coeficiente de variação (coefficient of variation); $\mathrm{R}^{2}=$ coeficiente de determinação (coefficient of determination).

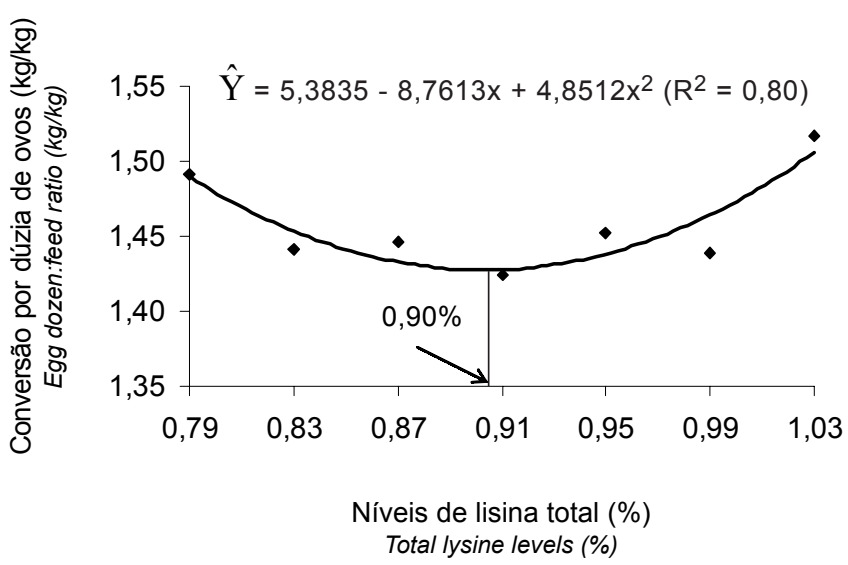

Figura 3 - Conversão por dúzia de ovos em função dos níveis de lisina total na ração.

Figure 3 - Egg dozen feed conversion as affected by the dietary total lysine levels.

A gravidade específica da casca dos ovos não foi alterada pelos níveis de lisina da ração. Isso sugere que a qualidade da casca não é influenciada pela suplementação da ração com lisina, pelo fato de que este aminoácido não causa aumento dos ovos, comprovado pela falta de efeito da lisina sobre esta característica. Alguns autores têm sustentado que o peso do ovo é um dos fatores da alteração na qualidade da casca (Roland, 1976; Hamilton, 1978), pois os ovos mais pesados tendem a apresentar casca mais 


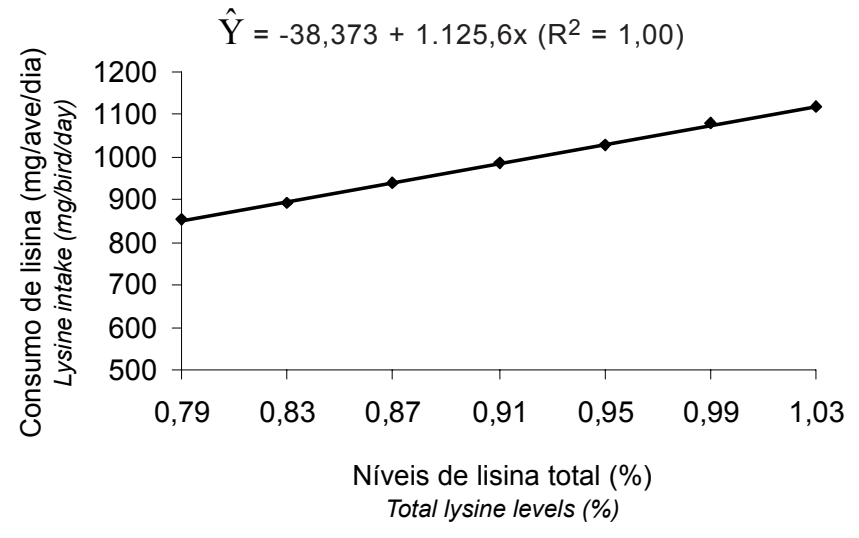

Figura 4 - Consumo de lisina em função dos níveis de lisina total na ração.

Figure 4 - Lysine intake as affected by the dietary total lysine levels.

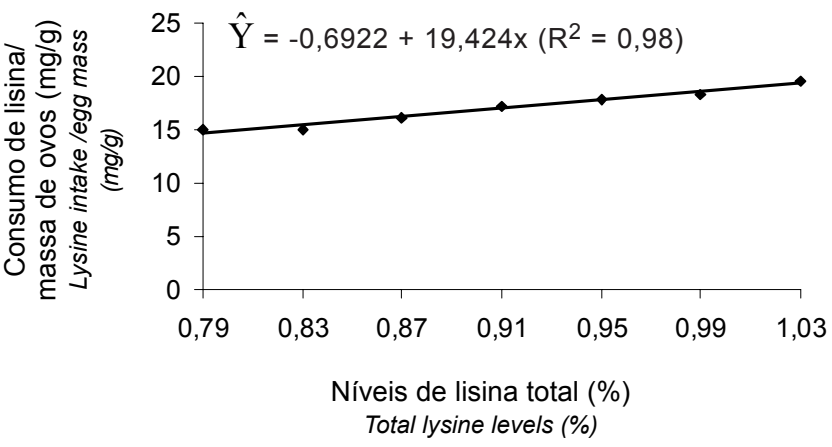

Figura 5 - Consumo de lisina/massa de ovos em função dos níveis de lisina total da ração.

Figure 5 - Egg mass/lysine intake as affected by the dietary total lysine levels.

fraca, pela incapacidade da galinha de depositar cálcio na mesma proporção para crescimento e peso dos ovos. Semelhantemente ao resultado obtido neste estudo, Novak et al. (2004) também não observaram variação na gravidade específica da casca de ovos produzidos por poedeiras leves à medida que os níveis de lisina na ração foram elevados.

Houve efeito linear positivo dos níveis de lisina sobre o consumo de lisina (Figura 4) e o consumo de lisina por massa de ovos $(\mathrm{P} \leq 0,05)$ (Figura 5).

$\mathrm{O}$ aumento do consumo de lisina foi proporcional à elevação da concentração deste aminoácido nas rações, a exemplo de estudos com galinhas poedeiras (Goulart, 1997), pintinhas (Silva et al., 2000a) e codornas na fase de produção (Ribeiro et al., 2003).

A pior eficiência de conversão da lisina em massa de ovos produzida com o aumento da suplementação de lisina é compatível com o excesso de consumo deste aminoácido. Trabalhando com frangos de corte, Silva et al.
(2001) observaram redução da eficiência protéica à medida que o teor de proteína da dieta aumentou.

A recomendação de lisina total $(0,92 \%)$ deste trabalho foi feita com base na produção de ovos e considerando que este valor atende ao estimado com base na conversão alimentar por dúzia de ovos $(0,90 \%)$. A estimativa de $0,92 \%$ de lisina total equivale a $0,84 \%$ de lisina digestível ou à ingestão de 996 e $910 \mathrm{mg}$ de lisina total e digestível/ave/dia, respectivamente, considerando um consumo diário médio de ração de 108,3 g/ave. Este resultado é semelhante à recomendação de $0,92 \%$ de lisina total para aves pesando $1,6 \mathrm{~kg}$ de PV, descrita por Rostagno et al. (2005), e próximo aos $893 \mathrm{mg}$ de lisina digestível/ave/dia obtidos por Sá et al. (2004) para poedeiras leves durante o pico de postura.

\section{Conclusões}

As exigências de lisina total e digestível estimadas com base na produção de ovos foram de 0,92 e $0,84 \%$ ou de 996 e $910 \mathrm{mg} /$ ave/dia, durante o pico de postura de poedeiras semipesadas.

\section{Literatura Citada}

BAIÃO, N.C.; FERREIRA, M.O.O.; BORGES, F.M.O. et al. Efeito dos níveis de metionina da dieta sobre o desempenho de poedeiras comerciais. Arquivo Bras ileiro de Medicina Veterinária e Zootecnia, v.51, n.3, p.271-274, 1999.

BAKER, D.H.; BATAL, A.B.; PARR, T.M. et al. Ideal ratio (relative to lysine) of tryptophan, threonine, isoleusine and valine for chicks during the second and third weeks posthatch. Poultry Science, v.81, n.4, p.485-494, 2002.

BARBOSA, B.A.C.; SOARES, P.R.; ROSTAGNO, H.S. et al. Exigência nutricional de lisina para galinhas poedeiras de ovos brancos e marrons, no segundo ciclo de produção. 2. Características produtivas. Revista Brasileira de Zootecnia, v. 28, n.3, p.534-541, 1999.

CARVALHO, D.C.O.; ALBINO, L.F.T.; ROSTAGNO, H.S. et al. Exigências nutricionais de lisina para poedeiras leve no período final de postura, submetidas a estresse térmico. Suplemento da Revista Brasileira de Ciência Avícola, v.6, p.102, 2003.

D'MELLO, J.P.F. Farm animal: metabolism and nutrition. Edimburg: Cabi, 2000. 438p.

GADELHA, A.C.; DAHLKE, F.; FARIA FILHO, D.E. et al. Interação entre arginina e lisina altera as respostas produtivas e a incidência de problemas de pernas em frangos de corte. Suplemento da Revista Brasileira de Ciência Avícola, v.5, p. 75, 2003.

GOULART, C.C. Exigências nutricionais de lisina para poedeiras leves e semipesadas. Viçosa, MG: Universidade Federal de Viçosa, 1997. 52p. Dissertação (Mestrado em Zootecnia) - Universidade Federal de Viçosa, 1997.

HAMILTON, R.G.M. Observation on the changes in the physical characteristics the influence egg shell quality in the strains of white Leghorn. Poultry Science, v.57, p.1192-1198,1978.

HEMPE, J.M.; LAUXEN, R.C.; FAGAGE, J.E. A rapid determination of egg weight and specific gravity using computerized collection system. Poultry Science, v.67, p.902-907, 1988.

KOELKEBECK, K.W.; BAKER, D.H.; HAN, Y. et al. Research note: effect of excess lysine, methionine, threonine, or 
tryptophan on production performance of laying hens.Poultry Science, v.70, p.1651-1653, 1991.

MENDONÇA JR., C.X.; LIMA, F.R. Efeito dos níveis de proteína e de metionina da dieta sobre o desempenho de galinhas poedeiras após a muda forçada. Journal Veterinary Research and Animal Science, v.36, p.332-338, 1999.

NATIONAL RESEARCH COUNCIL - NRC. Nutrient requeriment of poultry. 9.ed. Washington, D.C.: National Academic Press, 1994. 155p.

NOVAK, C.L.; YAKOUT, H.S.; SCHEIDELER, S. The combined effects of dietary lysine and total sulfur amino acid level on egg production parameters and egg components in dekalb delta laying hens. Poultry Science, v.83, p.977-984, 2004.

OKUMURA, J.; YAMAGUCHI, K. Effect of excess individual essential amino acids in diets on chicks. Poultry Science, v. 17, p.135-139, 1980

PACK, M. Proteína ideal para frangos de corte. Conceito e posição atual. In: CONFERÊNCIA APINCO DE CIÊNCIAS E TECNOLÓGIA AVÍCOLA, 1995, Curitiba. Palestras... Curitiba: Fundação Avícola de Ciência e Tecnologia Avícolas, 1995. p.95-110.

PINTO, R.; FERREIRA, A.S.; DONZELE, J.L.; Exigência de lisina para codornas japonesas em postura. Revista Brasileira de Zootecnia, v.32, n.5. p.1182-1189, 2003.

RIBEIRO, M.L.G.; SILVA , J.H.V.; DANTAS, M.O. et al. Exigências nutricionais de lisina para codornas durante a fase de postura, em função do nível de proteína da ração. Revista Brasileira de Zootecnia, v.32, n.1, p.156-161, 2003.

RIBEIRO, M.L.G.; SILVA, J.H.V.; COSTA, F.G.P. et al. Efeito dos níveis de lisina e de proteína sobre os parâmetros de carcaças e teor de proteína dos ovos de codornas. Suplemento da Revista Brasileira de Ciência Avícola, v.4, p. 68, 2002.

ROLAND, D.A. Recent developments in egg shell quality. Feedstuffs, v.48, n.29, p.31, 1976

ROSTAGNO, H.S.; ALBINO, L.F.T.; DONZELE, J.L. et al. Tabelas brasileiras para suínos e aves: Composição de alimentos e exigências nutricionais. 2.ed. Viçosa, MG: Universidade Federal de Viçosa, 2005. 186p.

ROSTAGnO, H.S.; ALBINO, L.F.T.; DONZELE, J.L. et al. Tabelas brasileiras para suínos e aves: composição de alimentos e exigências nutricionais. Viçosa, MG: Universidade Federal de Viçosa, 2000. 141p.

SÁ, L.M.; GOMES, P.C.; ROSTAGNO, H.S. et al. Exigência de lisina para poedeiras leves no período de 34 a 50 semanas de idade. In.: REUNIÃO ANUAL DA SOCIEDADE BRASILEIRA DE ZOOTECNIA, 2004, 40., Campo Grande. Anais... Campo Grande: Sociedade Brasileira de Zootecnia, 2004. (CD-ROM)

SCHUTTE, J.B.; DE JONG, J. Requeriment of the laying hen for súlfur amino acids. Poultry Science, v.73, p.274-280, 1994.

SCHUTTE, J.B.; SMINK, W. Requeriment of the laying hens for apparent fecal digestible lysine. Poultry Science, v.77, p.697-701, 1998.
SILVA, J.H.V.; ALBINO, L.F.T.; ROSTAGNO, H,S. et al. Exigência de lisina para aves de reposição de 0 a 6 semanas de idade. Revista Brasileira de Zootecnia, v.29, n.6, p.1777-1785, $2000 \mathrm{a}$

SILVA, J.H.V.; ALBINO, L.F.T.; ROSTAGNO, H,S. et al. Exigência de lisina para aves de reposição de 7 a 12 semanas de idade. Revista Brasileira de Zootecnia, v.29, n.6, p.1786-1794, $2000 \mathrm{~b}$

SILVA, J.H.V.; ALBINO, L.F.T.; ROSTAGNO, H,S. et al. Exigência de lisina para aves de reposição de 13 a 20 semanas de idade. Revista Brasileira de Zootecnia, v.29, n.6, p.1795-1802, $2000 \mathrm{c}$.

SILVA, J.H.V.; ALBINO, L.F.T.; NASCIMENTO, A.E. Níveis de energia e relações energia:proteína para frangos de corte de 22 a 42 dias de idade. Viçosa. Revista Brasileira de Zootecnia, v.30, n.6, p.1791-1800, 2001.

SILVA, J.H.V.; LIMA, M.R.; ARAÚJO, J.A. et al. Relacionamento lisina e arginina para poedeiras durante o pico de postura. In: CONGRESSO NORDETINO DE PRODUÇÃO ANIMAL, 3. 2004, Campina Grande. Anais... Campina Grande: Sociedade Nordestina de Produção Animal, 2004. (CD-ROM)

SILVA, J.H.V.; JORDÃO FILHO, J.; SILVA, E.L. Por quê formular dietas para poedeiras com base no conceito de proteína ideal? Revista Ave World, v.3, n.3, p.50-57, 2005.

SILVA, J.H.V.; SANTOS, V.J.; RIBEIRO, M.L.G. Alta densidade de criação durante o segundo ciclo de postura. Suplemento da Revista Brasileira de Ciência Avícola, v.5, p.1, 1999.

SILVA, E.L.; SILVA, J.H.V.; JORDÃO FILHO, J. et al. Plano de nutrição para codornas européias de 1 a 42 dias de idade. Suplemento da Revista Brasileira de Ciência Avícola, v.5, p.62, 2003.

TOGASHI, C.K.; FONSECA, J.B.; SOARES, R.T.R.N. et al. Determinação de níveis de metionina + cistina para poedeiras semipesadas alimentadas com rações contendo levedura seca. Revista Brasileira de Zootecnia, v.31, n.3, p.1426-433, 2002 (supl.).

UNIVERSIDADE FEDERAL DE VIÇOSA - UFV. SAEG - Sistema para Análise Estatística e Genética. Versão 5.0. Viçosa, MG: Fundação Arthur Bernardes, 1993. 59p.

VALÉRIO, S.R.; OLIVEIRA, R.F.M.; DONZELE, J.L. et al. Níveis de lisina digestível em rações mantendo-se ou não a relação aminoacídica, para frangos de corte de 1 a 21 dias de idade, sob condições de estresse por calor. Revista Brasileira de Zootecnia, v.32, n.2, p.361-371, 2003 